\section{Enhancement of Somatic Embryogenesis and Production of Developmentally Arrested Embryos in Nigella sativa L.}

\author{
Hamid Elhag ${ }^{1}$, Mahmoud M. El-Olemy, and Mansour S. Al-Said \\ Department of Pharmacognosy, College of Pharmacy, King Saud University, \\ P.O. Box 2457, Riyadh-11451, Saudi Arabia
}

Additional index words. Nigella sativa, somatic embryogenesis, arrested development, thymoquinone, p-cymene, $\alpha$-pinene

\begin{abstract}
Somatic embryogenesis of Nigella sativa was investigated with the objective of inducing and isolating somatic embryos for biosynthetic studies. Callus cultures were initiated from leaf, stem, and root explants of axenic seedlings on MSB5 basal medium supplemented with kinetin $(0.46 \mu \mathrm{M})$ and $2,4-\mathrm{D}(4.5$ or $13.5 \mu \mathrm{M})$ or NAA $(5.4$ or $16.2 \mu \mathrm{M})$ in the dark. Cultures initiated and subcultured on medium containing NAA produced friable callus with numerous roots regardless of explant type. Cultures initiated, subcultured, or both, on medium with low 2,4-D concentration produced shiny embryogenic masses. These cultures differentiated into somatic embryos on medium containing NAA. The embryos developed into leafy structures on basal medium devoid of growth regulators. When the embryogenic callus was transferred to liquid medium containing NAA, numerous embryos and clusters of embryos were released into the liquid medium but, in contrast to solid medium, development remained arrested at the early embryonic stages. The developmentally arrested embryos were tested for production of active constituents of $N$. sativa oil. Chemical names used: 2,4-dichlorophenoxyacetic acid (2,4-D); $\alpha$-naphthaleneacetic acid (NAA); kinetin (K).
\end{abstract}

Nigella sativa L. (Ranunculaceae) is an important medicinal plant in the Middle East, Africa and Asia. The seed, known as "black seed or black cumin", has wide uses in Arabic and Asian traditional medicine. It is used to control coughs and asthma, as an anthelmintic, and as an appetite stimulant (El-Dakhakhny, 1963). The seed also exhibits antioxidant, antimicrobial, antiinflammatory, and immunostimulant activities (Shah et al, 1988; Houghton et al, 1995). The active constituents include primarily the volatile oil components, particularly thymoquinone, $\mathrm{p}$-cymene and $\alpha$-pinene (Houghton et al, 1995; Al-Ajmi, 1999).

Studies of $N$. sativa in vitro cultures have dealt mainly with establishment of cell cultures from various explants, nuclear cytology, differentiation, and propagation (Schmauder and Doebel, 1991). Cultures of Nigella spp. $(2 n=12)$ provided an excellent system for karyological studies due to the relatively large size of chromosomes (Gupta, 1972). Banerjee and Gupta (1975 a,b; 1976) induced somatic embryogenesis and regenerated plants from an Indian variety of $N$. sativa. In vitro propagation of $N$. sativa was also reported from axilliary

Received for publication 6 Nov. 2002.Accepted for publication 13 May 2003. We thank King Abdulaziz City for Science and Technology (KACST) for financial support (Project No. AT-15-39) and Zein A Elbashir, College of Administrative Sciences, King Saud Univ., Riyadh, for assistance with statistical analysis.

${ }^{1}$ To whom reprints request should be addressed Present address: Phone and fax, 770-909-1089.

E-mail: helhagus@yahoo.com bud multiplication and somatic embryogenesis (Kumar and Roy, 1996). In these studies, the biosynthetic capacity of $N$. sativa cultures was not reported. However, Schmauder and Doebel (1991) reported on the biosynthetic capacity of cell cultures of $N$. damascena, but formation of volatile oil components was not achieved. Because seed of $N$. sativa is the organ of interest, it is conceivable that embryos are linked to the biosynthetic process of active product(s). Thus, somatic embryogenesis was reinvestigated with the objective of inducing and isolating somatic embryos prior to germination and plant development for biosynthetic studies. This report describes a protocol optimized for the induction and interruption of development of somatic embryos from callus cultures of two widely used cultivars of $N$. sativa. The somatic embryos arrested at initial stages of development were tested for the production of the active constituents of $N$. sativa oil.

\section{Materials and Methods}

Plant material. Seeds of two cultivars of N. sativa, Ethiopian and Qassimi (Qassim is a region in the center of Saudi Arabia), were purchased from the local market in Riyadh in 1997. The seeds were surface sterilized by soaking in 70\% ethanol for 2-3 min., followed by washing $3 \times$ with sterile double-distilled water and soaking again in $30 \%$ sodium hypochlorite ( $14 \%$ chlorine) and final washing $3 \times$ with sterile water. The sterilized seeds were grown on sterile Heller-support filter paper dipped in liquid half strength Murashige and Skoog's basal medium
(1/2 MS) (Murashige and Skoog, 1962) supplemented with $3 \%$ sucrose. More than $50 \%$ seed germination was recorded after 2 weeks.

Induction of callus cultures. Leaf, stem, and root explants were taken from 1-month-old axenic seedlings ( $\approx 100 \mathrm{~mm}$ long). Sections of the explants were cultured on agar solidified ( $0.8 \%$ bactoagar) medium containing MSB5 as basal medium [the inorganic salts of $\mathrm{Mu}$ rashige and Skoog (1962) and (B5) vitamins (Gamborg's et al., 1968)], with 0.09 M sucrose, $0.46 \mu \mathrm{M}$ kinetin $(\mathrm{K})$, and 4.5 or $13.5 \mu \mathrm{M}$ of $2,4-\mathrm{D}$, or 5.4 or $16.2 \mu \mathrm{m}$ NAA. The medium was autoclaved for $15 \mathrm{~min}$. at $121^{\circ} \mathrm{C}$ and 20 psi. Partially cooled medium $\left(60\right.$ to $\left.80^{\circ} \mathrm{C}\right)$ was distributed into sterile plastic petri dishes $(90 \times$ $15 \mathrm{~mm}), 20 \mathrm{~mL}$ per dish. At least five explants were cultured per dish with 5-10 dishes per treatment $(\mathrm{n}=25-50)$. Cultures were kept in dark at $24 \pm 2{ }^{\circ} \mathrm{C}$ for callus induction and later transferred to light for growth and morphogenesis in a walk-in culture room maintained at a 16-h photoperiod from coolwhite fluorescent tubes $\left(80 \mu \mathrm{mol} \cdot \mathrm{m}^{-2} \cdot \mathrm{s}^{-1}\right)$. The experiment was repeated at least once.

Induction of somatic embryogenesis. Induction of somatic embryogenesis was attempted with callus induced on $2,4-\mathrm{D}(4.5 \mu \mathrm{M})$ containing medium after three subcultures in the dark (4 weeks each). This callus was subjected to three treatments:

A. Callus was subcultured on agar-solidified MSB5 medium containing NAA $(5.4 \mu \mathrm{M})$ for two subcultures in the light and then transferred to similar medium containing high NAA $(16.2 \mu \mathrm{M})$.

B. Callus was transferred to liquid MSB5 with reduced 2,4-D $(2.26 \mu \mathrm{M})$ for two subcultures and then plated on solid MSB5 containing NAA $(16.2 \mu \mathrm{M})$.

C. Callus maintained as in treatment A for several subcultures, was transferred to liquid MSB5 containing NAA $(16.2 \mu \mathrm{M})$ in flasks (100 mL/500-mL flask). The flasks were placed on a rotary shaker maintained at 100 rpm and subcultured every 3 weeks.

All cultures were observed and examined weekly for embryogenesis and photomicrographs taken. The frequency of somatic embryogenesis in cultures grown on solid medium was estimated by counting the number of embryogenic clusters per callus clump per plate after the eighth subculture. The mean values were recorded together with the percentage of shoots formed per callus clump. The frequency of embryogenesis in liquid medium was estimated by counting the number of embryogenic clusters per flask after separation from suspension culture.

The cultures of the arrested embryos (treatment C) were analysed for the production of the active constituents of $N$. sativa oil, normally produced by the seeds (Al-Ajmi, 1999).

Statistical analysis. A completely randomized design was used in this experiment with at least six petri dishes and four flasks as replicates. The data involving the two cultivars (Ethiopian and Qassimi) and the two treatments (A and C), was treated as a $2 \times 2$ 
factorial with two levels each (Table 1). The effect of the three treatments (A, B, and C) was tested for the Qassimi cultivar, and treated as one factor experiment at three levels (Table 2 ). The data were subjected to analysis of variance (ANOVA) procedures (Hicks, 1973), and analyzed with the general linear model of SPSS (Version 10, Software Release 10.01 (Oct. 1999), SPPS Inc., Chicago).

\section{Results and Discussion}

Induction of Callus cultures. Leaf, stem, and root explants of the two N. sativa cultivars, began to form callus after 4 weeks of culture in the dark. Both growth regulators supported callus induction after 6 weeks, but a higher percentage was achieved on NAA containing medium. The callus induced on NAA containing medium $(5.4$ or $16.2 \mu \mathrm{M})$ produced multiple roots from various explants. The process of root formation in such callus was noted in earlier studies (Banerjee and Gupta, 1975a). The roots multiplied and elongated in liquid medium devoid of growth regulators and turned green when transferred to light. When NAA induced callus was subcultured on 2,4-D containing medium, the process of rhizogenesis ceased.

Somatic embryogenesis. Somatic embryogenesis could not be achieved in callus initially induced on NAA containing medium. However, transfer of callus initially induced and maintained for three subcultures on 2,4-D $(4.5 \mu \mathrm{M})$ containing medium in the dark to a medium supplemented with NAA $(5.4 \mu \mathrm{M})$ for two subcultures resulted in the formation of white-to-yellow leaf-like structures originating within the callus tissues. Further transfer of these tissues to medium with higher NAA $(16.2 \mu \mathrm{M})$ in the light (treatment A), resulted in the formation of white creamy embryogenic clusters embedded in the callus mass. Microscopic examination of the 8th-10th subcultures on similar medium revealed various stages of embryo development in the same callus clump. The embryos occurred in clusters of 2-6 white creamy or yellow globular and heart-shaped embryos attached together (Fig. 1, a and b). Some of the embryos developed into torpedoshaped and cotyledonary embryos on the same medium (Fig. 1, c and d). Germination or complete plantlet formation was not observed. However, the cotyledonary embryos developed into elongated green leaves on MSB5 medium without radical formation. In comparison, Banerjee and Gupta (1975b; 1976) reported maturation and germination of $N$. sativa embryoids on MS medium supplemented with IAA and casein hydrolysate.

The formation of embryos in clusters and their asynchronous development made it difficult to accurately estimate the frequency of embryogenesis. Therefore, the counts of embryogenic clusters and embryos with developed green cotyledonary leaves were done separately. The Ethiopian cultivar callus resulted in the highest frequency of embryogenic clusters per petri dish (37.7) and per callus clump (5.4), than the Qassimi cultivar callus (21.3 and 3.0, respectively) on treatment A (Table 1). However, the Qassimi cultivar callus formed more cotyledonary embryos $(28 \%)$ than the Ethiopian cultivar callus (19.5\%) under the same conditions. The Qassimi cultivar callus also formed more developed embryos (66\%) when grown on treatment $\mathrm{B}$, but with lower embryogenic frequency per petri dish and per

Table 1. Effect of treatments A and C on somatic embryogenesis in callus cultures of Ethiopian (ET) and Qassimi (QA) cultivars of Nigella sativa.

\begin{tabular}{|c|c|c|c|c|c|c|}
\hline Treatments $^{2}$ & Cultivar & $\begin{array}{c}\text { No. of } \\
\text { embryogenic } \\
\text { clusters per } \\
\text { plate or flask }\end{array}$ & $\begin{array}{c}\text { No. of } \\
\text { embryogenic } \\
\text { clusters per } \\
\text { callus clump } \\
\end{array}$ & $\begin{array}{c}\text { Callus } \\
\text { clumps with } \\
\text { shoots }(\%)\end{array}$ & $\begin{array}{l}\text { No. of } \\
\text { shoots per } \\
\text { clump }\end{array}$ & $\begin{array}{c}\text { Mean } \\
\text { length of } \\
\text { shoots } \\
(\mathrm{mm}) \\
\end{array}$ \\
\hline \multirow[t]{2}{*}{$\mathrm{A}$} & ET & $37.7 b^{x}$ & 5.4 & 19.5 & 2.5 & 3.0 \\
\hline & QA & $21.3 \mathrm{c}$ & 3.0 & 28.6 & 1.0 & 5.0 \\
\hline \multirow[t]{2}{*}{ C } & ET & $62.4 \mathrm{a}$ & --- & --- & --- & --- \\
\hline & QA & $36.6 \mathrm{~b}$ & --- & --- & --- & --- \\
\hline
\end{tabular}

${ }^{2}$ Treatments: $\mathrm{A}=$ callus induced on 2,4-D $(4.5 \mu \mathrm{M})$, subcultured and maintained on solidified MSB5 medium containing NAA $(16.2 \mu \mathrm{M})$ in the light; $\mathrm{C}=$ callus maintained on protocol A for several subcultures, then transferred to liquid MSB5containing (NAA $16.2 \mu \mathrm{M}$ ) in flasks and shaken at $100 \mathrm{rpm}$.

${ }^{y}$ Means of at least six culture dishes with an average of seven callus clumps per dish for the agar solidified medium, and four flasks for the liquid medium.

${ }^{x}$ Mean separation within column by least significant difference, $P \leq 0.05$.

Table 2. Effect of the three treatments A, B, and C on embryo production in callus cultures of Qassimi cultivar of N. sativa.

\begin{tabular}{lccccc}
\hline & $\begin{array}{c}\text { No. of } \\
\text { embryogenic } \\
\text { clusters per } \\
\text { petri dish or flask }\end{array}$ & $\begin{array}{c}\text { No. of } \\
\text { embryogenic } \\
\text { clusters per } \\
\text { callus clump }\end{array}$ & $\begin{array}{c}\text { Callus } \\
\text { clumps with } \\
\text { shoots (\%) }\end{array}$ & $\begin{array}{c}\text { No. of } \\
\text { shoots } \\
\text { per clump }\end{array}$ & $\begin{array}{c}\text { Mean length } \\
\text { of shoots } \\
(\mathrm{mm})\end{array}$ \\
\hline $\mathrm{A}$ & $21.3 \mathrm{~b}^{\mathrm{y}}$ & 3.0 & 28.6 & 1.0 & 5.0 \\
$\mathrm{~B}$ & $11.0 \mathrm{~b}$ & 1.6 & 66.0 & 3.5 & 7.0 \\
$\mathrm{C}$ & $36.6 \mathrm{a}$ & -- & -- & --- & --- \\
\hline
\end{tabular}

${ }^{2}$ Treatments: $\mathrm{A}=$ callus induced on 2,4-D $(4.5 \mu \mathrm{M})$ in the dark, subcultured and maintained on solid MSB5 containing NAA $(16.2 \mu \mathrm{M})$ in the light. B = callus induced on 2,4-D $(4.5 \mu \mathrm{M})$, subcultured to liquid MSB5 containing 2,4-D $(2.26 \mu \mathrm{M})$ for two subcultures, then plated on solid MSB5 containing NAA $(16.2 \mu \mathrm{M})$ in light. C = callus maintained on protocol A for several subcultures, then transferred to liquid MSB5 containing NAA $(16.2 \mu \mathrm{M})$ in flasks and shaken at $100 \mathrm{rpm}$.

${ }^{\mathrm{y}}$ Mean separation within column by least significant difference, $P \leq 0.05$. callus clump (Table 2) as compared to treatment A, indicating an inverse relationship between embryogenic frequency and development of embryos. In comparison, Liu et al (2002) reported that plating of embryogenic suspension cultures of coriander initially induced on 2,4-D containing MS medium, onto basal medium supplemented with inorganic nitrogen and a lower concentration of 2,4-D enhanced the frequency of both somatic embryogenesis and development of embryos into plantlets.

Enhancement of somatic embryogenesis and interruption of embryo development in the two cultivars occurred when the embryogenic callus clumps that were maintained on treatment A for several subcultures, were transferred to liquid medium of similar composition i.e. (treatment C). This resulted in the release of whitish or creamy embryogenic clusters 3 weeks after transfer to the liquid medium (Fig. 1e). The clusters appeared separated from the original callus clumps and freely suspended in the medium. None of the embryos within these clusters germinated or developed beyond the globular or heart-shaped stages even after prolonged subcultures in the liquid medium. Somatic embryogenesis and germination of somatic embryos of $N$. sativa cultures was reported to occur in hormone-free liquid MS medium supplemented with L-glutamine (Kumar and Roy, 1996). In comparison, somatic embryos of Malva sp. developed into heart- and torpedoshaped forms on MS medium supplemented with NAA and BA, but failed to germinate on this medium or on a medium devoid of growth regulators (Kintzios, 2002).

Analysis of the data for embryogenic frequency in the two cultivars with respect to treatments A and C, revealed significant differences between cultivar treatments (Table 1). The highest embryogenic frequency was obtained with the Ethiopian cultivar under treatment $C$. Significant differences between the treatments were also obtained with the Qassimi cultivar cultures (Table 2). Treatment $\mathrm{C}$ again gave significantly higher embryogenic frequency than treatments A and B. However, treatment A did not differ significantly from B using the least significance difference (LSD) test.

In this study, the proliferation of embryogenic clusters in $N$. sativa continued through subculture 20 (4 weeks each) on solid MSB5 using treatment $\mathrm{A}$, compared to subculture 8 in an earlier report (Banerjee and Gupta, 1976). Transfer of embryogenic callus clumps to liquid-medium (treatment $\mathrm{C}$ ), resulted in increased number of embryogenic clusters and prevented their asynchronous development. Kumar and Roy (1996) reported increased somatic embryogenesis in $N$. sativa in liquid MS medium supplemented with glutamine, compared to similar solid medium. The use of liquid cultures (batch or bioreactors) has been suggested for synchronous and mass proliferation of somatic embryos in carrot and nerine (Osuga and Komamine, 1994; Lilien-Kipnis et al., 1994; Onishi et al., 1994) and is needed for biosynthetic studies and automation (Redenbaugh et al., 1991; Vasil, 1994).

The above-mentioned results indicate the importance of the primary culture, particu- 


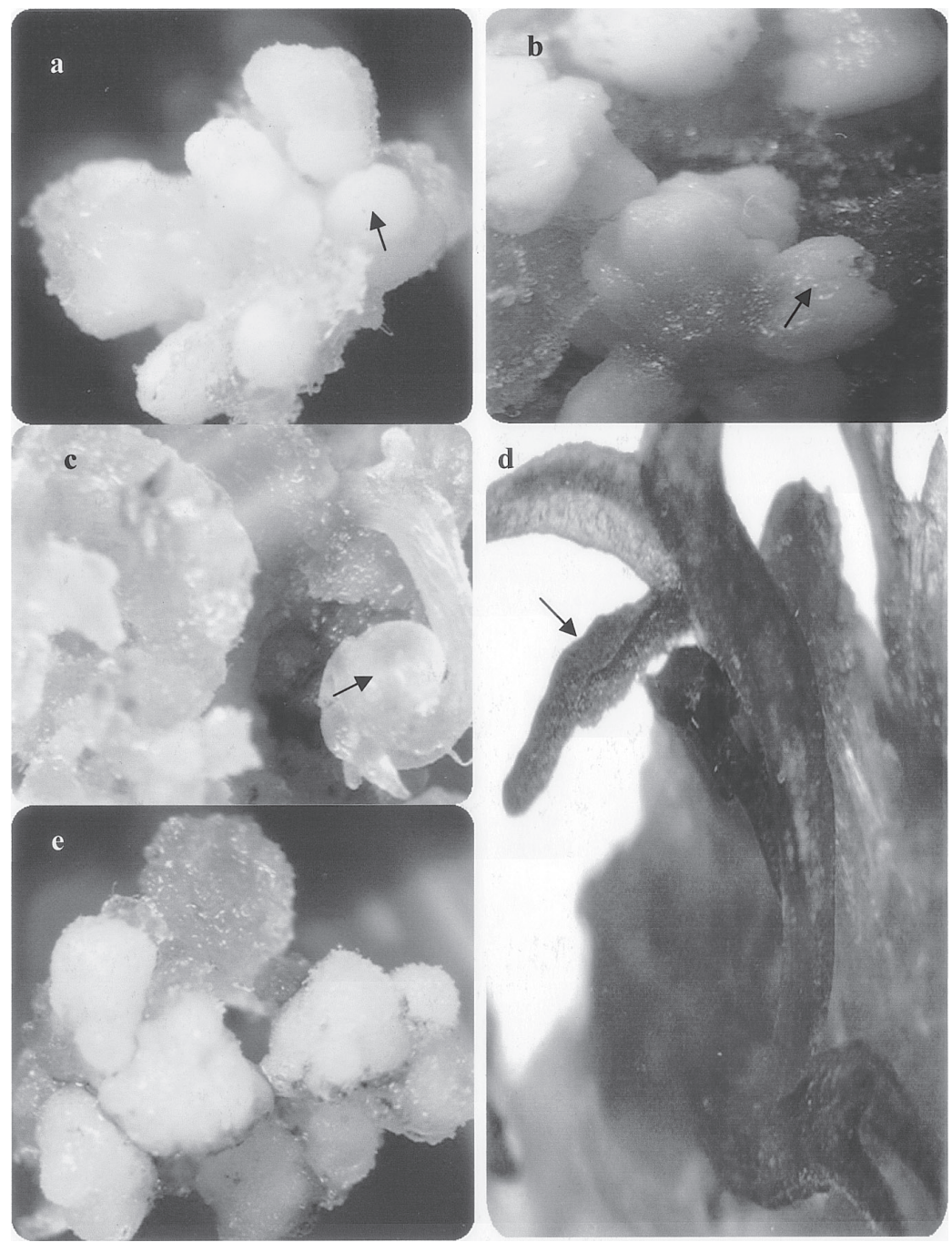

Fig. 1. Photomicrographs of $N$. sativa somatic embryos showing (a) a single cluster with globular embryos (b) heart-shaped embryos (c) torpedo embryo (d) green cotyledonary embryos (e) undeveloped somatic embryos from liquid culture (Treatment C) $(20 x-30 x)$.

larly the type of auxin used, on subsequent morphogenetic events (Ammirato, 1983). Thus, the auxin 2,4-D was found essential for the induction of pre-embryogenic cells, but subsequent development required NAA. This is quite similar to what was reported in celery (Nadel, et al., 1989) and in Brassica nigra (Mehta et al., 1993).

Analysis of the extracts from developmentally arrested embryos revealed the presence of $\alpha$-pinene, a major component and one of the active principles of $N$. sativa volatile oil, together with traces of thymoquinone, the main active principle of $N$. sativa (Houghton et al, 1995; Al-Ajmi, 1999). These results indicate a correlation between differentiation and secondary product formation observed with other plant tissue cultures (Sierra et al, 1991; Van Geldre et al, 1997; Kintzios, 2002).

In the present study, a protocol for the induction and enhancement of somatic embryogenesis in Nigella sativa is reported. Such protocol may be manipulated and optimized to allow normal embryo development for propagation or to arrest normal development for biosynthetic studies or for production of synthetic seeds.

\section{Literature Cited}

Al-Ajmi, M.F. 1999. Pharmacological and biochemical studies on the black seed Nigella sativa dethymoquinonated volatile oil and some of the constituents in rodents. Dept. of Pharmacology, College of Pharmacy, King Saud Univ., Riyadh, Saudi Arabia. M.Sc. Thesis.

Ammirato, P.V. 1983. The regulation of somatic embryo development in plant cell cultures: Suspension culture techniques and hormone requirements. Biotechnology 1:68-74.

Banerjee, S. and S. Gupta. 1975a. Morphogenesis in tissue cultures of different organs of Nigella sativa. Physiol. Plant. 33:185-187.

Banerjee, S. and S. Gupta. 1975b. Embryoid and plantlet formation from stock cultures of Nigella sativa. Physiol. Plant. 34:243-245.

Banerjee, S. and S. Gupta. 1976. Embryogenesis and differentiation in Nigella sativa leaf callus in vitro. Physiol. Plant. 38:115-120.

El-Dakhakhny, M. 1963. Isolation of thymoquinone from essential oil of Nigella sativa L. seeds. Planta Med. 11:465-475.

Gamborg, O.L., R.A. Miller, and K. Ojima. 1968. Nutrient requirements of suspension cultures of soybean root cells. Exp. Cell Res. 50:151-158.

Gupta, S. 1972. Tissue culture of Nigella sativa 1. The behaviour of nucleus. Experientia.
28:441-443

Hicks, C.R. 1973. Fundamental concepts in the design of experiments. Holt, Rinehart, and Winston, New York.

Houghton, P.J., R. Zaka, P.D. Hera, and J.R.S. Hoult. 1995. Fixed oil of Nigella sativa and derived thymoquinone inhibit eicosanoid generation in Leukocytes and membrane lipid peroxidation. Planta Med. 61:33-66.

Kintzios, S.E. 2002. Malva sp. (Mallow): In vitro culture and the production of secondary metabolites. p. 137-155. In: T. Naguta and Y. Ebizuka (eds.). Biotechnology in agriculture and forestry, Vol. 51. Medicinal and Aromatic Plants XII, Springer-Verlag, Berlin, Heidelberg.

Kumar, S. and S.G. Roy. 1996. Rapid in vitro propagation of Nigella sativa by axillary bud multiplication and somatic embryogenesis. Cytobios. 87 (349):99-106.

Lilien-Kipnis, H., N. Azizbekova, and M.Ziv. 1994 Scaled-up proliferation and regeneration of Nerine in liquid cultures. Part II. Ontogency of somatic embryos and bulblet regeneration. Plant Cell Tissue Organ Cult. 39:117-123.

Liu, J.R., S.W. Kim, and S.C. OH. 2002. In vitro culture and the production of secondary metabolites in Coriandrum sativum L. (Coriander). p. 13-21. In: T. Nagata and Y. Ebizuka (eds.). Biotechnology in agriculture and forestry, Vol. 51. Medicinal and Aromatic Plants XII. Springer-Verlag, Berlin, Heidelberg.

Mehta, U.J., S. Hazra, and A.F. Mascarenhas. 1993. Somatic embryogenesis and in vitro flowering in Brassica nigra. In Vitro Cell. Dev. Biol. 29:1-4.

Murashige, T. and F. Skoog. 1962. Arevised medium for rapid growth and bioassay with tobacco tissue cultures. Physiol. Plant. 15:473-497.

Nadel, B.L., A. Altman, and M. Ziv. 1989. Regulation of somatic embryogenesis in celery cell suspension. 1. Promoting effects of mannitol on somatic embryo development. Plant Cell Tissue Organ Cult. 18:181-189.

Onishi, N., Y. Sakamoto, and T. Hirosawa. 1994. Synthetic seeds as an application of mass production of somatic embryos. Plant Cell Tissue Organ Cult. 39:137-145.

Osuga, K. and A. Komamine. 1994. Synchronization of somatic embryogenesis from carrot cells at high frequency as a basis for the mass production of embryos. Plant Cell Tissue Organ Cult. 39:125-135.

Redenbaugh, K., J.A. Fujii, and D. Slade. 1991. Synthetic seed technology. p. 35-74. In: I.K. Vasil (ed.). Scale-up and automation in plant propagation. Academic Press, San Diego.

Schmauder, H.P. and P. Doebel. 1991. Nigella spp.: In vitro culture. Regeneration, and the formation of secondary metabolites. p. 311-338. In: Y.P.S. Bajaj (ed.). Biotechnology in agriculture and forestry, Vol. 15. Medicinal and Aromatic Plants III. Springer-Verlag, Berlin, Heidelberg.

Shah, A.H., A. Khatibi, A.M. Ageel, and M.O.M. Tanira. 1988. Phytochemical and antimicrobial screening of some medicinal plants used in Saudi folk medicine. Pakistan J. Pharm. Sci. $1: 53$

Sierra, M.I., R. Van Des Heijden, J. Schripsema, and R. Verpoorte. 1991. Alkaloid production in relation to differentiation in cell and tissue cultures of Tabernaemontana pandacaqui. Planta Med. 57:543-547.

Van Geldre, E., A. Vergauwe, and E. Van den Eeckhout. 1997. State of art of the production of the antimalarial compound artemisinin in plants. Plant Molecular Biol. 33:199-209.

Vasil, I.K. 1994. Automation of plant propagation. Plant Cell Tissue Organ Cult. 39:105-108. 